\title{
Larval toxocariasis with persistent eosinophilia in a patient with chronic hepatitis B - a case report
}

\author{
Gheorghe Plăcintă*, Tatiana Știrbu \\ From The 9th Edition of the Scientific Days of the National Institute for Infectious Diseases Prof Dr Matei Bals \\ Bucharest, Romania. 23-25 October 2013
}

\section{Background}

The associated forms of larval toxocariasis and hepatitis have a particular evolution with various manifestations depending on the prevalence of pathology. In both cases this liver involvement and specific antiparasitic treatment may aggravate the liver disease.

\section{Case report}

We present the case of a patient with clinical symptoms of lightheadedness, fatigue, memory disturbances, tremor of the limbs, nausea and blurred vision. The laboratory tests found the presence of hepatomegaly, interstitial nodules on ultrasound exam, positive HBsAg, hypereosinophilia (40\%) and increased titers of anti-Toxocara 71.98. After diagnosing the larval toxocariasis, we prescribed treatment with albendazole and hepatoprotective drugs for 14 days. After a month, the general condition improved with the reduction of cytolysis syndrome, eosinophilia (14\%) and the titer of anti-Toxocara (28). The patient was followed-up for 7 years, during which there were periodic relapses requiring repeated courses of benzimidazole derivatives. It is worth mentioning that the pronounced worsening of the general condition in 2010 was caused by the association of other parasitic invasions (giardiasis and ascaridiasis) which also resulted in a marked increase of eosinophilia (60\%), increased titers of anti-Toxocara (73.47) and a high level of transaminases (ALT - $87 \mathrm{U} / \mathrm{l})$. After treatment with albendazole the general condition improved with the disappearance of clinical signs and the reduction of cytolysis syndrome.

\footnotetext{
* Correspondence: gheorgheplacinta@yahoo.com Department of Infectious Diseases, Faculty for Continuing Medical Education, Nicolae Testemițanu State Medical and Pharmacy University, Chişinău, Republic of Moldova
}

\section{Conclusion}

The case shows the chronic nature of the Toxocara invasion with the possibility of repeated relapses and wavy evolution of the disease, with a strong correlation between the intensity of invasion and clinical picture. The presence of an association with liver pathology will only lead to worsening the evolution, as was demonstrated by the data in the literature.

Published: 16 December 2013

doi:10.1186/1471-2334-13-S1-P77

Cite this article as: Plăcintă and Știrbu: Larval toxocariasis with persistent eosinophilia in a patient with chronic hepatitis $B-$ a case report. BMC Infectious Diseases 2013 13(Suppl 1):P77.

Submit your next manuscript to BioMed Central and take full advantage of:

- Convenient online submission

- Thorough peer review

- No space constraints or color figure charges

- Immediate publication on acceptance

- Inclusion in PubMed, CAS, Scopus and Google Scholar

- Research which is freely available for redistribution
C Biomed Central

๑ 2013 Plăcintă and Știrbu; licensee BioMed Central Ltd. This is an Open Access article distributed under the terms of the Creative Commons Attribution License (http://creativecommons.org/licenses/by/2.0), which permits unrestricted use, distribution, and reproduction in any medium, provided the original work is properly cited. 